\title{
JIG FOR MEASURING ENDOTRACHEAL TUBE LENGTHS
}

B. E. WELSH, M.B., B.S., F.F.A.R.C.S.(ENG.), AND A. W. CoNN, M.D., F.R.C.P.(C)

The STANDARD TYPE OF endotracheal tube used at the Hospital for Sick Children, Toronto, is uncuffed and made of clear plastic. These tubes are supplied in sealed packets and sterilized by gamma-irradiation by the manufacturers.

The hospital treats patients from birth to 19 years of age, and hence anaesthetists use endotracheal tubes of all lengths and diameters. Two standard lengths are issued for each calibre, one for oral and one for nasal use (Table I).

The jig illustrated in Figure 1 is intended to check the tube length rapidly without destroying the packet seal. Tubes are placed in slots of the appropriate length for their calibre; if necessary, they can be cut quickly to size using the open end of the slot as the marker.

The jig was made in the hospital workshops. Tube outlines in the full range of sizes are fretted out of a $\frac{1 / 4}{4}$ inch Perspex sheet which is then cemented to a similar blank sheet. The lengths of the slots are accurate to $1 \mathrm{~mm}$; the widths are those of the external diameters of the tubes.

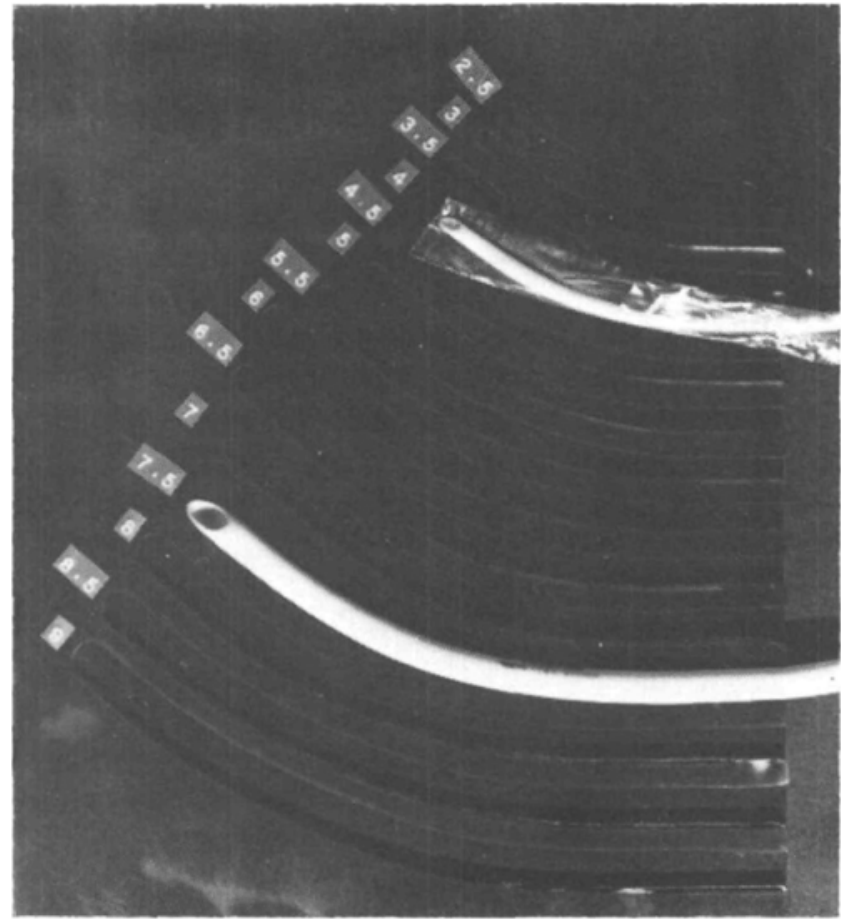

ACKNOWLEDGMENTS
Figure 1. Plastic jig for measuring length of endotracheal tubes of various diameters.

Our thanks are due to Mr. Wainman who actually made the jigs, and to Mrs. V. Brady, R.N., who pointed out the need for them. 


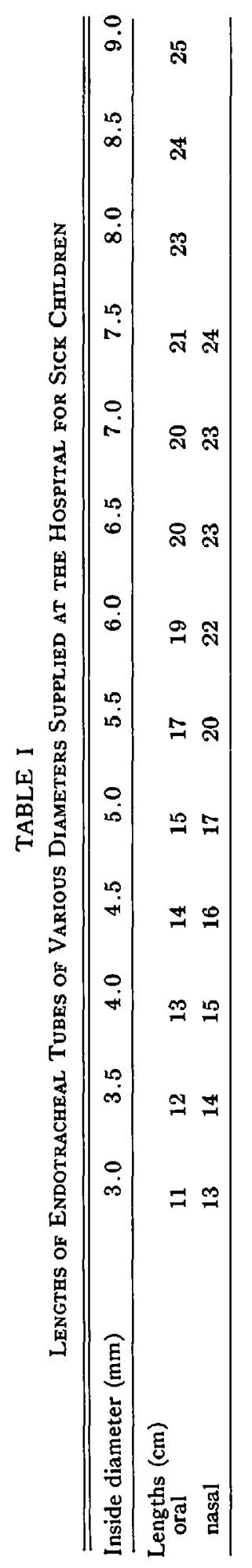

